\title{
Magnetic resonance spectroscopy detection of high lipid levels in intraaxial tumors without central necrosis: a characteristic of malignant lymphoma
}

\author{
Fumiyuki Yamasaki, MD, PhD, ${ }^{1}$ Takeshi Takayasu, MD, ${ }^{1}$ Ryo Nosaka, MD, ${ }^{1}$ \\ Vishwa Jeet Amatya, MBBS, PhD, ${ }^{3}$ Aidos Doskaliyev, MD, PhD, ${ }^{1}$ Yuji Akiyama, ${ }^{4}$ \\ Atsushi Tominaga, MD, PhD, ${ }^{1}$ Yukio Takeshima, MD, PhD, ${ }^{3}$ Kazuhiko Sugiyama, MD, PhD, ${ }^{2}$ \\ and Kaoru Kurisu, MD, PhD' ${ }^{1}$
}

\begin{abstract}
Departments of ${ }^{1}$ Neurosurgery and ${ }^{3}$ Pathology, Institute of Biomedical and Health Sciences, Hiroshima University, Kasumi, Minami-ku; and Department of ${ }^{2}$ Clinical Oncology and Neuro-oncology Program, and ${ }^{4}$ Department of Clinical Radiology, Hiroshima University Hospital, Hiroshima, Japan
\end{abstract}

OBJECT The differentiation of malignant lymphomas from gliomas or malignant gliomas by conventional MRI can be difficult. The authors studied Gd-enhanced MR images to obtain a differential diagnosis between malignant lymphomas and gliomas without central necrosis or cystic changes and investigated the diagnostic value of single-voxel proton MR spectroscopy ( $\left.{ }^{1} \mathrm{H}-\mathrm{MRS}\right)$ using different parameters, including lipid levels.

METHODS This was a retrospective study of patients with primary malignant CNS lymphoma $(n=17)$ and glioma ( $\mathrm{n}$ = 122 [Grades I, II, III, and IV in 10, 30, 33, and 49 patients, respectively]) who were treated between 2007 and 2013. The authors focused on 15 patients with homogeneously enhanced primary malignant CNS lymphomas and 7 homogeneously enhanced gliomas. Images of all the included tumors were acquired with ${ }^{1} \mathrm{H}-\mathrm{MRS}$ at $3 \mathrm{~T}$, and the diagnoses were histologically confirmed.

RESULTS Using a short echo time ${ }^{1} \mathrm{H}-\mathrm{MRS}$, large lipid peaks were observed in all 17 patients with a malignant lymphoma, in 39 patients (79.6\%) with a Grade IV glioma, and in 10 patients (30.3\%) with a Grade III glioma. A focus on homogeneously enhanced tumors revealed large lipid peaks in 15 malignant lymphomas that were free of central necrosis on Gd-enhanced T1-weighted images. Conversely, in the 7 homogeneously enhanced gliomas (glioblastoma and anaplastic astrocytoma, $n=2$ each; anaplastic oligodendroglioma, diffuse astrocytoma, and pilomyxoid astrocytoma, $n=1$ each), lipid peaks were small or absent.

CONCLUSIONS Large lipid peaks on ${ }^{1} \mathrm{H}-\mathrm{MRS}$ images of tumors without central necrosis were characteristic of malignant lymphomas. Conversely, small or absent lipid peaks in intraaxial tumors without central necrosis were strongly suggestive of glioma.

http://thejns.org/doi/abs/10.3171/2014.9.JNS14106

KEY WORDS malignant lymphoma; proton MR spectroscopy; lipids; glioma; oncology

$\mathrm{P}$ RIMARY CNS lymphomas, a rare malignant form of non-Hodgkin's lymphoma, account for 3\%-6\% of all primary brain neoplasms. ${ }^{4}$ There has been an increase in the incidence of malignant lymphoma in the last 3 decades. The differentiation of malignant lymphomas from gliomas or malignant gliomas by conventional MRI can be difficult. Malignant lymphomas and glioblastomas require different treatments; glioblastomas are treated by extensive resection, whereas malignant lymphomas are usually addressed by biopsy. Therefore, a differential diagnosis is of high clinical relevance. Moreover, even with advanced MRI techniques that yield physiological in-

\footnotetext{
ABBREVIATIONS ADC = apparent diffusion coefficient; $\mathrm{ADC}_{\mathrm{MIN}}=$ minimum absolute $\mathrm{ADC} ; \mathrm{b}-\mathrm{n}=\mathrm{b}$ value of $\mathrm{n}$ sec/mm²; cho = choline; $\mathrm{Cr}=\mathrm{creatine} ; \mathrm{DWI}=\mathrm{diffusion}$ weighted imaging; FLAIR = fluid-attenuated inversion recovery; ${ }^{1} \mathrm{H}-\mathrm{MRS}=$ proton MR spectroscopy; $\mathrm{ml}=$ myoinositol; $\mathrm{MRS}=\mathrm{MR}$ spectroscopy; $\mathrm{NAA}=\mathrm{N}$-acetyl aspartate; $\mathrm{ROI}=$ region of interest; $\mathrm{VOI}=$ volume(s) of interest.

SUBMITTED January 10, 2014. ACCEPTED September 10, 2014.

INCLUDE WHEN CITING Published online March 6, 2015; DOI: 10.3171/2014.9.JNS14106.

DISCLOSURE The authors report no conflict of interest concerning the materials or methods used in this study or the findings specified in this paper. The following grants funded this study: grant-in-aid nos. 25462262 and 23592091 from the Japan Society for the Promotion of Science Grant-in-Aid for Scientific Research.
} 
formation, it is often difficult to differentiate malignant lymphomas from nonneoplastic diseases such as neuroBehçet disease, multiple sclerosis, and acute demyelinating encephalomyelitis.

Magnetic resonance spectroscopy (MRS) is a noninvasive technique for obtaining biochemical information from the volume of interest (VOI) in tissues. ${ }^{8,23} \mathrm{In}$ vivo proton MRS ('H-MRS) provides important information on tumor activity and tumor-tissue characteristics. The usefulness of ${ }^{1} \mathrm{H}-\mathrm{MRS}$ parameters in the differential diagnosis of brain tumors has been reported. ${ }^{1,14}$ Among these parameters, lipid peaks can be effectively detected, especially at a short echo time. In brain tumors, the presence of lipids often indicates the presence of necrotic tissue, which is considered to be an indicator of malignancy and a poor prognosis. ${ }^{17,29,36}$ Because malignant brain tumors tend to exhibit central necrosis on Gd-enhanced T1-weighted images, central necrosis inside the VOI is reflected by lipid peaks on ${ }^{1} \mathrm{H}-\mathrm{MRS}$ images. For the analysis of specific tumor characteristics, it is important to select the VOI only in Gd-enhanced lesions. However, because the signal-tonoise ratio from the pixel level of the VOI is low, it is difficult to avoid signals from necrotic or cystic lesions even when using the multivoxel ${ }^{1} \mathrm{H}-\mathrm{MRS}$ technique.

We used Gd-enhanced MRI to establish a differential diagnosis between malignant lymphomas and gliomas without central necrosis or cystic changes and examined the diagnostic value of ${ }^{1} \mathrm{H}$-MRS from the perspective of lipid peaks. We found that the presence on short echo time ${ }^{1} \mathrm{H}-\mathrm{MRS}$ images of large lipid peaks in tumors without central necrosis is a characteristic of malignant lymphomas.

\section{Methods \\ Patients}

This retrospective study was approved by the Hiroshima University Hospital's institutional review board; the requirement for written patient consent was waived. To protect patient privacy, we removed all identifiers from our records after the completion of our analyses.

Between 2007 and 2013, we treated 30 patients with malignant lymphoma at our institution. We excluded 13 tumors because they were metastatic malignant lymphomas $(\mathrm{n}=7)$ or their size was too small for setting a VOI (n =6). Consequently, 17 malignant lymphomas (in 6 males and 11 females), 2 of which were tumors with central necrosis, were included in the study. The 15 lymphomas without central necrosis were homogeneously enhanced on T1-weighted images; they were the focus of this study.

In that same period, we also treated 143 patients with a newly diagnosed surgically confirmed glioma. We excluded 21 tumors because they were not examined by ${ }^{1} \mathrm{H}-\mathrm{MRS}$ $(\mathrm{n}=12)$, their size was too small for setting a VOI $(\mathrm{n}=$ 3 ), or their spectra were of poor quality $(n=6)$, as indicated by an increased line width of the water resonance by 3 or more SDs above the mean line width of all tumor spectra. ${ }^{27,34}$ Consequently, our study included 122 gliomas (in 71 males and 51 females); 7 were homogeneously enhanced on T1-weighted images and were the focus of this study.

\section{MRI Studies}

All MRI studies were performed using a 3.0-T superconducting system (Signa Excite HD 3.0 T, versions 12 [January 2007 to March 2010] and 15 [April 2010 onward]; GE Medical Systems]. The MRI studies were performed in 3 orthogonal planes and included nonenhanced T1-weighted images (TR $450 \mathrm{msec}$, TE $18 \mathrm{msec}$, FOV 22 $\times 22 \mathrm{~cm}$, matrix size $256 \times 192 / 1$ excitation, section thickness $6 \mathrm{~mm}$, intersection gap $1.0 \mathrm{~mm}, 2$ acquisitions), T2weighted images (TR $4800 \mathrm{msec}$, TE $100 \mathrm{msec}$, echo train length 18 , FOV $22 \times 22 \mathrm{~cm}$, matrix size $512 \times 320 / 2$ excitations, section thickness $6 \mathrm{~mm}$, intersection gap $1.0 \mathrm{~mm}$, 1 acquisition), FLAIR images (TR 10,000 msec, TE 140.0 msec, inversion recovery time $2400.0 \mathrm{msec}$, FOV $22 \times 22$ $\mathrm{cm}$, matrix size $288 \times 160 / 1$ excitations, section thickness $6 \mathrm{~mm}$, intersection gap $1.0 \mathrm{~mm}, 2$ acquisitions), and T2*weighted images (TR $600.0 \mathrm{msec}$, TE $12 \mathrm{msec}$, FOV $22 \times$ $22 \mathrm{~cm}$, matrix size $320 \times 192 / 1$ excitation, section thickness $6 \mathrm{~mm}$, intersection gap $1.0 \mathrm{~mm}, 1$ acquisition).

Diffusion-weighted imaging (DWI) was performed with $b$ values of 1000 and $4000 \mathrm{sec} / \mathrm{mm}^{2}$ (b-1000 and b-4000, respectively). The effective gradient was 40 $\mathrm{mT} / \mathrm{m}$, and the slew rate was $150 \mathrm{mT} / \mathrm{m} / \mathrm{msec}$. We used an 8-channel phased-array head coil with the following imaging parameters: TR $5000 \mathrm{msec}$ and TE $73.2 \mathrm{msec}$ (b1000), TR $5000 \mathrm{msec}$ and TE $100 \mathrm{msec}$ (b-4000), number of excitations 1 , FOV $22 \times 22 \mathrm{~cm}$, slice thickness $6 \mathrm{~mm}$, intersection gap $1.0 \mathrm{~mm}$, number of slices 20 , data acquisition matrix $128 \times 128$, and 2 acquisitions. The scan times were 20 and 40 seconds for $b-1000$ and b-4000, respectively.

Transverse, sagittal, and coronal spin-echo T1-weighted images were acquired after the intravenous administration of a Gd-based contrast medium and using the following parameters: TR $450 \mathrm{msec}$, TE $18 \mathrm{msec}$, FOV $18 \times 18 \mathrm{~cm}$, matrix size $288 \times 192$, section thickness $6 \mathrm{~mm}$, intersection gap $1.0 \mathrm{~mm}$, and 2 acquisitions. The Gd-enhanced pattern of each tumor was defined as having no, focal, heterogeneous, ring, or homogeneous enhancement.

\section{Proton MRS}

For ${ }^{1} \mathrm{H}-\mathrm{MRS}$, we applied the point-resolved spectroscopic method (probe-P; TR $2000 \mathrm{msec}$, TE $144 \mathrm{msec}$, 2048 data points, 64 signals acquired) with a circularly polarized head coil. Additional spectra with a short (30-msec) TE were also acquired. To guide the single-voxel spectroscopic examinations, we used enhanced T1-weighted images for enhanced tumors and T2-weighted FLAIR images for nonenhanced tumors. Under 3D control, the rectangular ${ }^{1} \mathrm{H}-\mathrm{MRS}$ voxel was placed on the solid tumor area; efforts were made to avoid contamination by surrounding normal-appearing tissue, the skull base, any hemorrhagic lesions, and the ventricular system and to include enhanced tumor lesions in patients with an enhanced tumor and FLAIR high-intensity lesions in patients with a nonenhanced tumor. The voxel size was between $15 \times 15$ $\times 15 \mathrm{~mm}$ (volume $3.4 \mathrm{~cm}^{3}$ ) and $20 \times 20 \times 20 \mathrm{~mm}$ (volume $8 \mathrm{~cm}^{3}$ ); the estimated disease fraction in the VOI exceeded $60 \%-100 \%$ in each patient. Spatial suppression pulses were applied to the outside of the voxel to reduce spectral contamination; global and localized shimming on the 
TABLE 1. Lipid expression levels of the gliomas and malignant lymphomas

\begin{tabular}{|c|c|c|c|c|c|}
\hline \multirow[b]{2}{*}{ Tumor Type \& Grade } & \multirow[b]{2}{*}{ No. of Patients } & \multicolumn{4}{|c|}{ No. (\%) w/ Lipid Level of: } \\
\hline & & - & $1+$ & $2+$ & $3+$ \\
\hline \multicolumn{6}{|l|}{ Gliomas ( $n=122)$} \\
\hline \multicolumn{6}{|l|}{ Grade I } \\
\hline Total & 10 & $7(70.0)$ & $2(20.0)$ & $0(0)$ & $1(10.0)$ \\
\hline Pilocytic astrocytoma & 8 & 6 & 1 & 0 & 1 \\
\hline Ganglioglioma & 1 & 0 & 1 & 0 & 0 \\
\hline Papillary glioneuronal tumor & 1 & 1 & 0 & 0 & 0 \\
\hline \multicolumn{6}{|l|}{ Grade II } \\
\hline Total & 30 & $23(76.7)$ & $5(16.7)$ & $0(0)$ & $2(6.7)$ \\
\hline Diffuse astrocytoma & 5 & 3 & 2 & 0 & 0 \\
\hline Oligoastrocytoma & 13 & 11 & 2 & 0 & 0 \\
\hline Oligodendroglioma & 8 & 7 & 0 & 0 & 1 \\
\hline Pilomyxoid astrocytoma & 3 & 1 & 1 & 0 & 1 \\
\hline PXA & 1 & 1 & 0 & 0 & 0 \\
\hline \multicolumn{6}{|l|}{ Grade III } \\
\hline Total & 33 & $17(51.5)$ & $6(18.2)$ & $6(18.2)$ & $4(12.1)$ \\
\hline Anaplastic astrocytoma & 12 & 7 & 2 & 1 & 2 \\
\hline Anaplastic oligoastrocytoma & 12 & 7 & 3 & 1 & 1 \\
\hline Anaplastic oligodendroglioma & 8 & 3 & 1 & 4 & 0 \\
\hline Anaplastic PXA & 1 & 0 & 0 & 0 & 1 \\
\hline \multicolumn{6}{|l|}{ Anaplastic astrocytoma } \\
\hline \multicolumn{6}{|l|}{ Grade IV } \\
\hline Total & 49 & $5(10.2)$ & $5(10.2)$ & $2(4.1)$ & $37(75.5)$ \\
\hline Glioblastoma & 47 & 4 & 4 & 2 & 37 \\
\hline Gliosarcoma & 2 & 1 & 1 & 0 & 0 \\
\hline Lymphomas ( $n=17)$ & 17 & $0(0)$ & $0(0)$ & $5(29.4)$ & $12(70.6)$ \\
\hline
\end{tabular}

PXA = pleomorphic xanthoastrocytoma.

water proton and optimization of water suppression were performed, resulting in water-peak line widths of 2-4 Hz. All MR images covering the VOI selected for MRS were retrospectively assessed consensually by 3 of the authors (F.Y., T.T., and R.N.). Spectra of poor quality, ${ }^{27,34}$ identified by an increased line width of the water resonance (a measure of the field homogeneity in the VOI) of 3 or more SDs above the mean line width of all tumor spectra, were excluded from the final analyses. The line width of the water signal intensity was automatically measured and reported by the processing software. The relative signal intensities of choline (Cho), creatine (Cr), $N$-acetyl aspartate (NAA), and myoinositol (mI) were obtained by numeric integration of the fitted signals. The signals of lipid peaks were determined by their short TEs, because the relaxation time of a lipid is very short. Lipid peaks were defined as negative and undetectable $(-)$, positive and detectable (1+), strongly positive $(2+$, representing the second largest among all the peaks), and extremely strongly positive (3+, representing the largest among all the peaks).

\section{Apparent Diffusion Coefficient Maps and Calculations}

All apparent diffusion coefficient (ADC) maps were generated with software (FuncTool; GE Medical Systems).
They were obtained by calculating the signal intensities on diffusion-weighted images at 2 different $b$ values $(0$ and $1000 \mathrm{sec} / \mathrm{mm}^{2}$ for b-1000 ADC maps and 0 and $4000 \mathrm{sec} /$ $\mathrm{mm}^{2}$ for b-4000 ADC maps) on a pixel-by-pixel basis.

To determine the ADC, 2 independent readers (A.D. and F.Y.) manually placed regions of interest (ROIs) in tumor regions on b-1000 ADC maps and as close as possible in the same region of an approximately similar size (approximately $30 \mathrm{~mm}^{2}$ ) on the b-4000 ADC maps. The ROI were placed on enhanced lesions on contrast-enhanced T1-weighted MR images, as central as possible within the tumor. The number of ROI placed depended on the size of the observable part of the enhanced lesion. The ADC values of each tumor, based on 3-10 ROIs on the b-1000 and b-4000 ADC maps, were calculated, and the minimum absolute $\mathrm{ADC}\left(\mathrm{ADC}_{\mathrm{MIN}}\right)$ values were obtained.

\section{Histological Study}

Tumor specimens obtained by resection or biopsy were fixed in $10 \%$ phosphate-buffered formalin and embedded in paraffin. Representative slides were stained with $\mathrm{H} \& \mathrm{E}$ for a standard histological diagnosis according to WHO criteria by the consensus of 2 of the authors (V.J.A. and Y.T.), who were blinded to all clinical and radiological data. 
TABLE 2. Lipid expression levels of the ring-enhanced gliomas and malignant lymphomas

\begin{tabular}{|c|c|c|c|c|c|}
\hline \multirow[b]{2}{*}{ Tumor Type \& Grade } & \multirow[b]{2}{*}{ No. of Patients } & \multicolumn{4}{|c|}{ No. (\%) w/ Lipid Level of: } \\
\hline & & - & $1+$ & $2+$ & $3+$ \\
\hline \multicolumn{6}{|l|}{ Ring-enhanced gliomas $(n=46)$} \\
\hline \multicolumn{6}{|l|}{ Grade I } \\
\hline Total & 1 & $1(100)$ & $0(0)$ & $0(0)$ & $0(0)$ \\
\hline Pilocytic astrocytoma & 1 & 1 & 0 & 0 & 0 \\
\hline Grade II, total & 0 & & & & \\
\hline Grade III & 7 & $0(0)$ & $0(0)$ & $4(57.1)$ & $3(42.9)$ \\
\hline \multicolumn{6}{|l|}{ Total } \\
\hline Anaplastic astrocytoma & 2 & 0 & 0 & 1 & 1 \\
\hline Anaplastic oligoastrocytoma & 2 & 0 & 0 & 1 & 1 \\
\hline Anaplastic oligodendroglioma & 2 & 0 & 0 & 2 & 0 \\
\hline Anaplastic PXA & 1 & 0 & 0 & 0 & 1 \\
\hline Grade IV & 38 & $0(0)$ & $2(5.3)$ & $1(2.6)$ & $35(92.1)$ \\
\hline \multicolumn{6}{|l|}{ Total } \\
\hline Glioblastoma & 38 & 0 & 2 & 1 & 35 \\
\hline Ring-enhanced lymphomas $(n=2)$ & 2 & $0(0)$ & $0(0)$ & $0(0)$ & $2(100)$ \\
\hline
\end{tabular}

\section{Statistical Analysis}

Statistical analyses were performed with StatView software (version 5.0; SAS Institute). The relationship between MRS parameters that included the NAA-to-Cr, Cho-to-Cr, Cho-to-NAA, and mI-to-Cr ratios, the lipid levels, the averaged ADCs, and the different brain tumor types was evaluated with logistic analysis, the chi-square test, and the Mann-Whitney U-test; statistical significance was assigned when the $\mathrm{p}$ value was $<0.05$.

\section{Results}

\section{Patients and Glioma Grades}

The patients with a malignant lymphoma or glioma ranged in age from 36 to 78 years (mean 63.9 years, median 66 years) and from 1 to 85 years (mean 46.5 years, median 48.5 years), respectively. Of the 122 gliomas, 49 were Grade IV (47 glioblastomas and 2 gliosarcomas), 33 were Grade III (12 anaplastic astrocytomas, 12 anaplastic oligoastrocytomas, 8 anaplastic oligodendrogliomas, 1 anaplastic pleomorphic xanthoastrocytoma), 30 were Grade II (5 diffuse astrocytomas, 13 oligoastrocytomas, 8 oligodendrogliomas, 3 pilomyxoid astrocytomas, and 1 pleomorphic xanthoastrocytoma), and 10 were Grade I (8 pilocytic astrocytomas, 1 ganglioglioma, and 1 papillary glioneuronal tumor).

Gadolinium enhancement was absent in 21, focal in 21 , heterogeneous in 25, and homogeneous in 7 of the 122 gliomas; 47 were ring enhanced. For 1 patient with a glioblastoma and renal failure, we did not attempt to obtain enhanced images; the VOI was chosen on T2-weighted FLAIR images.

\section{Lipid Peaks Detected by Single-Voxel ${ }^{1} \mathrm{H}-\mathrm{MRS}$}

We first analyzed the lipid peaks of gliomas and lymphomas seen in ${ }^{1} \mathrm{H}-\mathrm{MRS}$ images (Table 1). In each of the
17 malignant lymphomas, we observed strong-positive (2+) or extremely strong-positive (3+) lipid peaks. Of the 122 Grade I-IV gliomas, 52 (42.6\%) manifested $2+$ or $3+$ lipid peaks.

Although lipid peaks were rare in lower-grade gliomas, we observed 2+ and $3+$ peaks in $30.3 \%$ of the Grade III and $79.6 \%$ of the Grade IV gliomas (low- vs high-grade gliomas, $\mathrm{p}<0.0001$, chi-square test; Grade III vs IV, $\mathrm{p}<$ 0.0001 , chi-square test). No unenhanced gliomas showed lipid peaks. The expression of $2+$ or $3+$ lipid peaks was statistically higher in malignant lymphomas than in highgrade gliomas ( $p=0.0014$, chi-square test).

\section{${ }^{1} \mathrm{H}$-MRS Findings in Ring-Enhanced Tumors}

Next, we focused on ring-enhanced tumors (Table 2). Both of the ring-enhanced malignant lymphomas showed $3+$ lipid peaks. We observed $2+$ or $3+$ lipid peaks in 43 of the 46 ring-enhanced gliomas. All but one glioma, a ringenhanced pilocytic astrocytoma, showed lipid peaks.

\section{${ }^{1} \mathrm{H}$-MRS Findings of Homogeneously Enhanced Tumors}

We then focused on the patients with homogeneously enhanced lymphomas and gliomas. Our MRS findings on malignant lymphomas and gliomas without central necrosis are summarized in Table 3 . All of the malignant lymphomas but none of the gliomas showed $2+$ or $3+$ lipid expression (Figs. 1 and 2) ( $\mathrm{p}=0.003$, chi-square test). Representative gliomas are shown in Figs. 3-5. When we analyzed the diagnostic value of ${ }^{1} \mathrm{H}-\mathrm{MRS}$ with respect to other parameters, including Cho, Cr, NAA, and mI, we detected no difference between malignant lymphomas and gliomas. Logistic analysis revealed that lipid expression differentiated between malignant lymphomas and gliomas and that logistic discriminant analysis clearly separated these tumors. 
TABLE 3. Malignant lymphomas and gliomas without central necrosis

\begin{tabular}{|c|c|c|c|c|c|c|c|c|c|c|c|c|c|}
\hline \multirow[b]{3}{*}{ Tumor Type } & \multirow{3}{*}{$\begin{array}{c}\text { Age } \\
\text { (yrs), } \\
\text { Sex }\end{array}$} & \multicolumn{2}{|c|}{ ADC Calculated From DWI } & \multirow{3}{*}{$\begin{array}{l}\text { VOI-Included } \\
\text { Tumor Vol } \\
(\%)\end{array}$} & \multicolumn{9}{|c|}{${ }^{1} \mathrm{H}-\mathrm{MRS}$ Data } \\
\hline & & \multirow{2}{*}{$\begin{array}{c}\mathrm{ADC}_{\mathrm{MIN}} \\
(\mathrm{b}-1000) \\
\left(\times 10^{-3} \mathrm{sec} / \mathrm{m}^{2}\right)\end{array}$} & \multirow{2}{*}{$\begin{array}{c}\mathrm{ADC}_{\mathrm{MIN}} \\
(\mathrm{b}-4000) \\
\left(\times 10^{-3} \mathrm{sec} / \mathrm{m}^{2}\right)\end{array}$} & & \multicolumn{4}{|c|}{ TE $144 \mathrm{msec}$} & \multicolumn{5}{|c|}{ TE $30 \mathrm{msec}$} \\
\hline & & & & & Cho & $\mathrm{Cr}$ & NAA & $\mathrm{ml}$ & Cho & $\mathrm{Cr}$ & NAA & $\mathrm{ml}$ & Lipids \\
\hline \multicolumn{14}{|l|}{$\begin{array}{l}\text { Homogeneously enhanced } \\
\text { intraaxial tumors }\end{array}$} \\
\hline Malignant lymphoma & $62, \mathrm{~F}$ & 0.854 & 0.462 & $\geq 60$ & 26 & 21 & 24 & ND & 55 & 47 & 80 & 24 & $2+$ \\
\hline Malignant lymphoma & $76, F$ & 0.592 & 0.352 & $\geq 60$ & 32 & 15 & 14 & ND & 34 & 40 & 55 & 72 & $2+$ \\
\hline Malignant lymphoma & $63, \mathrm{~F}$ & 0.648 & 0.420 & $\geq 60$ & 29 & 15 & 24 & ND & 79 & 42 & 76 & 30 & $2+$ \\
\hline Malignant lymphoma & $64, \mathrm{M}$ & 0.558 & 0.346 & $\geq 60$ & 21 & 8 & 10 & ND & 39 & 24 & ND & ND & $2+$ \\
\hline Malignant lymphoma & $72, \mathrm{~F}$ & 0.795 & 0.463 & $\geq 60$ & 27 & 8 & 12 & ND & 74 & ND & ND & ND & $3+$ \\
\hline Malignant lymphoma & $58, \mathrm{~F}$ & 0.835 & 0.469 & $\geq 60$ & 41 & 12 & 14 & ND & 97 & 35 & 61 & 32 & $3+$ \\
\hline Malignant lymphoma & $39, F$ & 0.645 & 0.385 & $\geq 80$ & 47 & 9 & 13 & 10 & 93 & 27 & ND & 35 & $3+$ \\
\hline Malignant lymphoma & $68, M$ & 0.593 & 0.386 & $\geq 80$ & 59 & ND & ND & ND & 113 & ND & ND & ND & $2+$ \\
\hline Malignant lymphoma & $60, \mathrm{M}$ & 0.499 & 0.260 & $\geq 80$ & 32 & 7 & ND & ND & 78 & ND & ND & ND & $3+$ \\
\hline Malignant lymphoma & $72, \mathrm{~F}$ & 0.693 & 0.389 & $\geq 80$ & 76 & 23 & 25 & 7 & 153 & 56 & 86 & 50 & $3+$ \\
\hline Malignant lymphoma & $67, \mathrm{~F}$ & 0.726 & 0.425 & $\geq 80$ & 27 & ND & ND & ND & 76 & 20 & ND & 24 & $3+$ \\
\hline Malignant lymphoma & $63, F$ & 0.863 & 0.523 & $\geq 80$ & 20 & ND & ND & ND & 75 & ND & ND & ND & $3+$ \\
\hline Malignant lymphoma & $76, F$ & 0.626 & 0.366 & $\geq 80$ & 44 & ND & ND & ND & 82 & ND & ND & ND & $3+$ \\
\hline Malignant lymphoma & $66, \mathrm{M}$ & 0.668 & 0.322 & $\geq 80$ & 63 & ND & ND & ND & 113 & 20 & ND & 32 & $3+$ \\
\hline Malignant lymphoma & $78, F$ & 0.542 & 0.350 & $\geq 80$ & 31 & 9 & ND & 12 & 68 & 43 & ND & 30 & $3+$ \\
\hline \multicolumn{14}{|l|}{ Gliomas } \\
\hline Diffuse astrocytoma & $47, \mathrm{M}$ & 1.10 & 0.594 & $\geq 60$ & 54 & 9 & 14 & ND & 99 & 19 & ND & 37 & $1+$ \\
\hline $\begin{array}{l}\text { Anaplastic oligodendro- } \\
\text { glioma }\end{array}$ & $48, F$ & 0.786 & 0.481 & $\geq 60$ & 88 & 30 & 46 & ND & 152 & 71 & 103 & 50 & - \\
\hline Pilomyxoid astrocytoma & $1, F$ & 1.92 & 1.09 & $\geq 80$ & 43 & 10 & 28 & ND & 71 & 29 & 69 & 31 & $1+$ \\
\hline Anaplastic astrocytoma & $54, \mathrm{~F}$ & 0.704 & 0.530 & $\geq 80$ & 46 & 9 & 14 & 7 & 77 & 34 & 37 & 34 & $1+$ \\
\hline Anaplastic astrocytoma & $65, F$ & 1.30 & 0.795 & $\geq 80$ & 44 & 12 & ND & ND & 85 & 33 & ND & 45 & $1+$ \\
\hline Glioblastoma & $31, \mathrm{M}$ & 0.705 & 0.495 & $\geq 80$ & 128 & 16 & 13 & 23 & 199 & ND & ND & ND & $1+$ \\
\hline Glioblastoma & $66, F$ & 0.690 & 0.457 & $\geq 80$ & 92 & 51 & 38 & 27 & 183 & 115 & 119 & 144 & - \\
\hline
\end{tabular}

$\mathrm{ND}=$ not detected.

\section{ADC of Gliomas and Malignant Lymphomas on Regular (b-1000) and High (b-4000) b-Value-Based DWI}

Finally, we checked the diagnostic value of DWI and the ADCs of homogeneously enhanced tumors. The ADC results for malignant lymphomas and gliomas without central necrosis are summarized in Table 3. Comparisons at b-1000 and b-4000 showed that the $\mathrm{ADC}_{\mathrm{MIN}}$ values of gliomas were higher than those of malignant lymphomas $(p=0.0220$ and 0.0010 , respectively, Mann-Whitney U-test) (Fig. 6). However, there was some overlap between gliomas and malignant lymphomas at both $b$ values.

\section{Discussion}

Our results show that high lipid peaks in tumors without central necrosis are a characteristic of malignant lymphomas and that their absence in intraaxial tumors without central necrosis is strongly suggestive of glioma. Although others reported that malignant lymphomas demonstrated massively elevated lipid resonances, some patients with high-grade gliomas, including glioblastomas, manifested high lipid peaks. . $7,12,16,25,36$ Our findings on Grade I-IV gliomas, especially ring-enhanced glioblastomas, are consistent with theirs. The earlier studies did not focus on homogeneously enhanced lesions; rather, they analyzed heterogeneously enhanced, ring-enhanced, and nonenhanced tumors together. Although it is important to set the ROI on enhanced tumor lesions and to avoid placement on nonenhanced lesions (e.g., areas of central necrosis), it can be difficult. Therefore, we focused on tumors without central necrosis (i.e., homogeneously enhanced tumors). We found that there was a characteristic difference in the presence and size of lipid resonance peaks on ${ }^{1} \mathrm{H}-\mathrm{MRS}$ images between homogeneously enhanced gliomas and malignant lymphomas. Consequently, although our and earlier studies showed a statistically significant difference in lipid expression between malignant lymphomas and high-grade gliomas, our findings on homogeneously enhanced tumors show that lipid expression differentiates between malignant lymphomas and high-grade gliomas. This finding is clinically relevant because homogeneously enhanced gliomas can be differentiated from malignant lymphomas by the absence of high lipid resonance peaks on ${ }^{1} \mathrm{H}-\mathrm{MRS}$ images. 

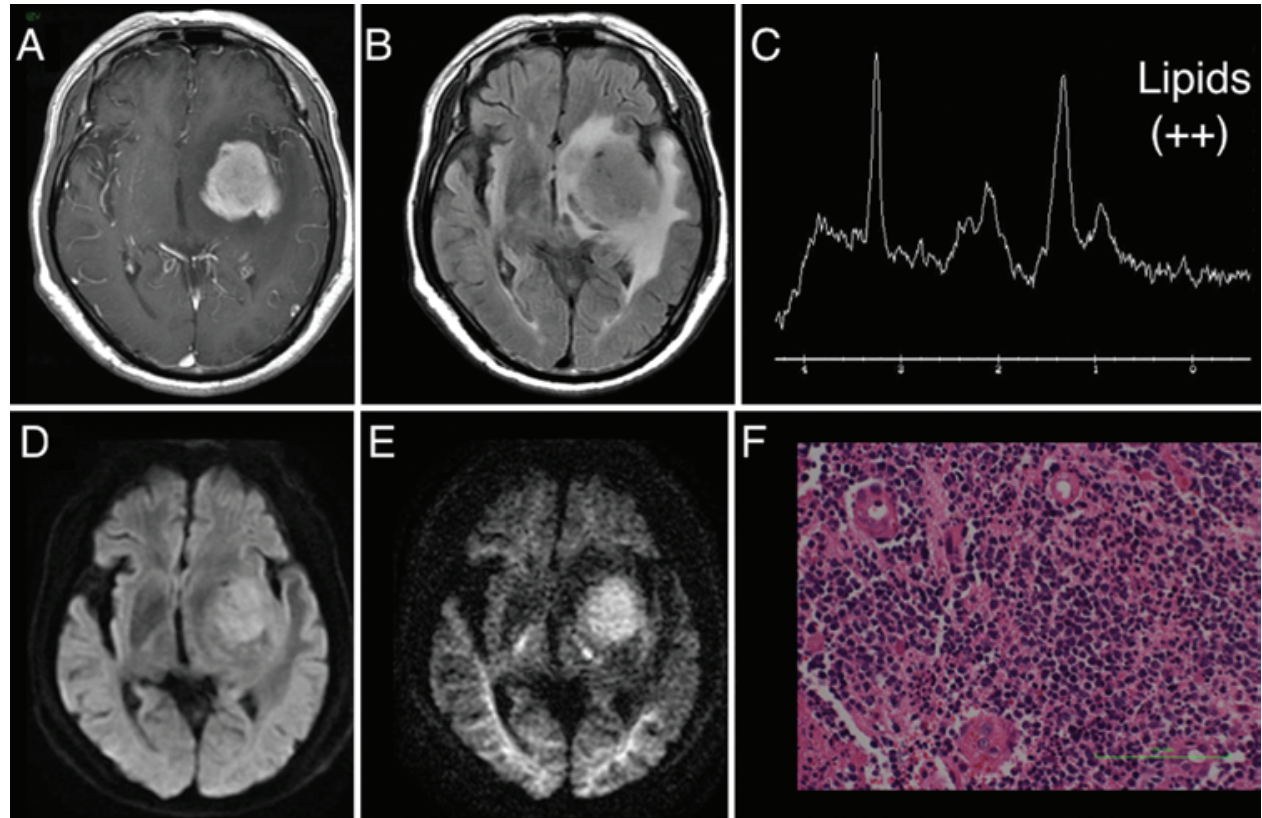

FIG. 1. Malignant lymphoma in a 68-year-old man. A: Axial contrast-enhanced T1-weighted image showing diffuse tumor enhancement in the left basal ganglia. B: Axial FLAIR image showing tumor isointensity and hyperintense peritumoral edema. C: Single-voxel ${ }^{1} \mathrm{H}-\mathrm{MRS}$ image (TE $35 \mathrm{msec}$ ) showing a tumor with a strong-positive (2+) lipid peak. D and E: Axial diffusionweighted images at b-1000 and b-4000, respectively, showing tumor hyperintensity. F: Photomicrograph of H \& E-stained tumor tissue. Bar $=100 \mu \mathrm{m}$. Figure is available in color online only.

The detection of high lipid peaks in malignant lymphomas has been suggested to reflect a high cell turnover and infiltration by macrophages..$^{13}$ The high lipid levels in these tumors without necrosis may be caused by the presence of activated or transformed lymphocytes or macro- phages, because these cell types can contain high levels of MR-visible lipids. ${ }^{18,19}$ Primary CNS lymphomas are hypercellular and comprise lymphoid cells and macrophages. ${ }^{21}$ Phagocytosis of cell membranes by infiltrated macrophages results in lipid signals. ${ }^{9}$ Lipid signals have
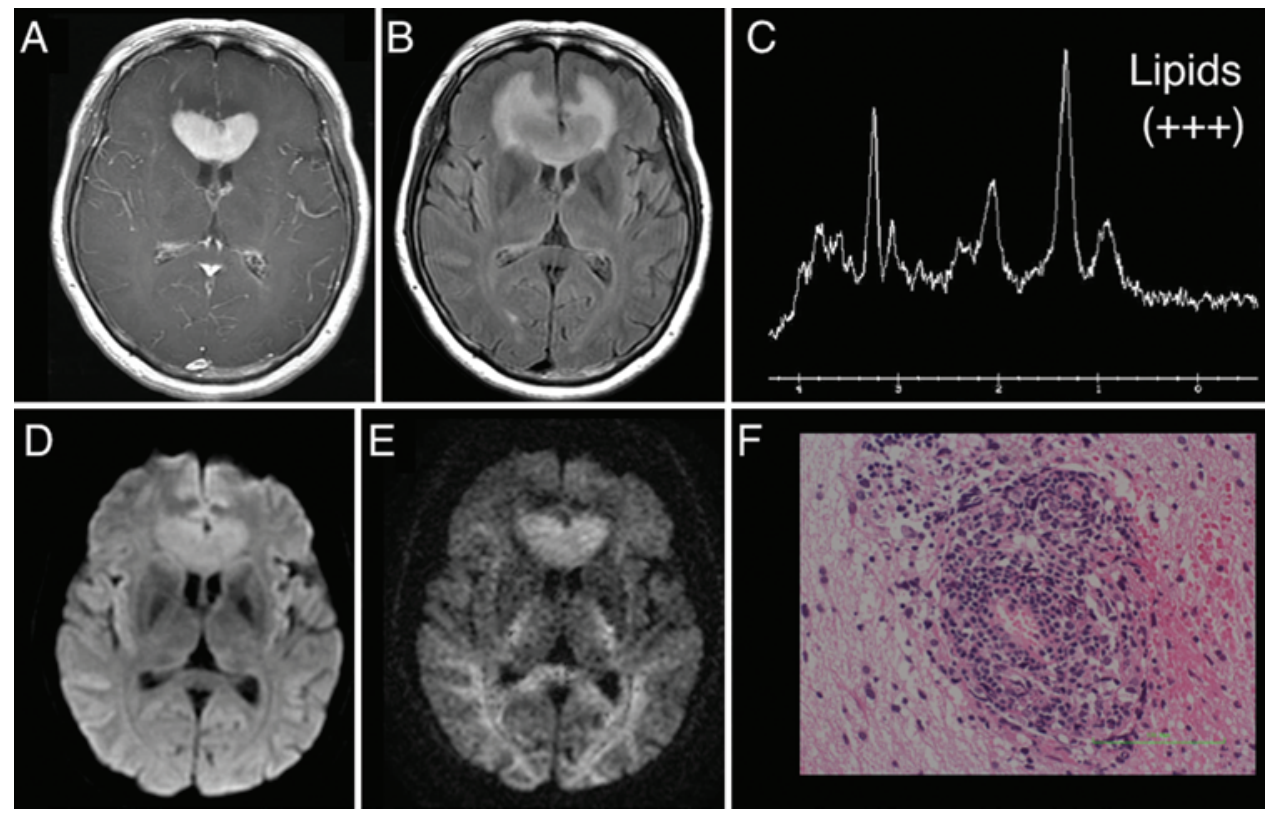

FIG. 2. Malignant lymphoma in a 61-year-old woman. A: Axial contrast-enhanced T1-weighted image showing diffuse tumor enhancement in the genu of the corpus callosum. B: Axial FLAIR image showing tumor isointensity to high intensity and hyperintense peritumoral edema. C: Single-voxel ${ }^{1} \mathrm{H}-\mathrm{MRS}$ image (TE $35 \mathrm{msec}$ ) showing a tumor with an extremely strong-positive (3+) lipid peak. D and E: Axial diffusion-weighted images at b-1000 and b-4000, respectively, showing tumor hyperintensity. F: Photomicrograph of $\mathrm{H} \& \mathrm{E}$-stained tumor tissue. Bar $=100 \mu \mathrm{m}$. Figure is available in color online only. 
F. Yamasaki et al.
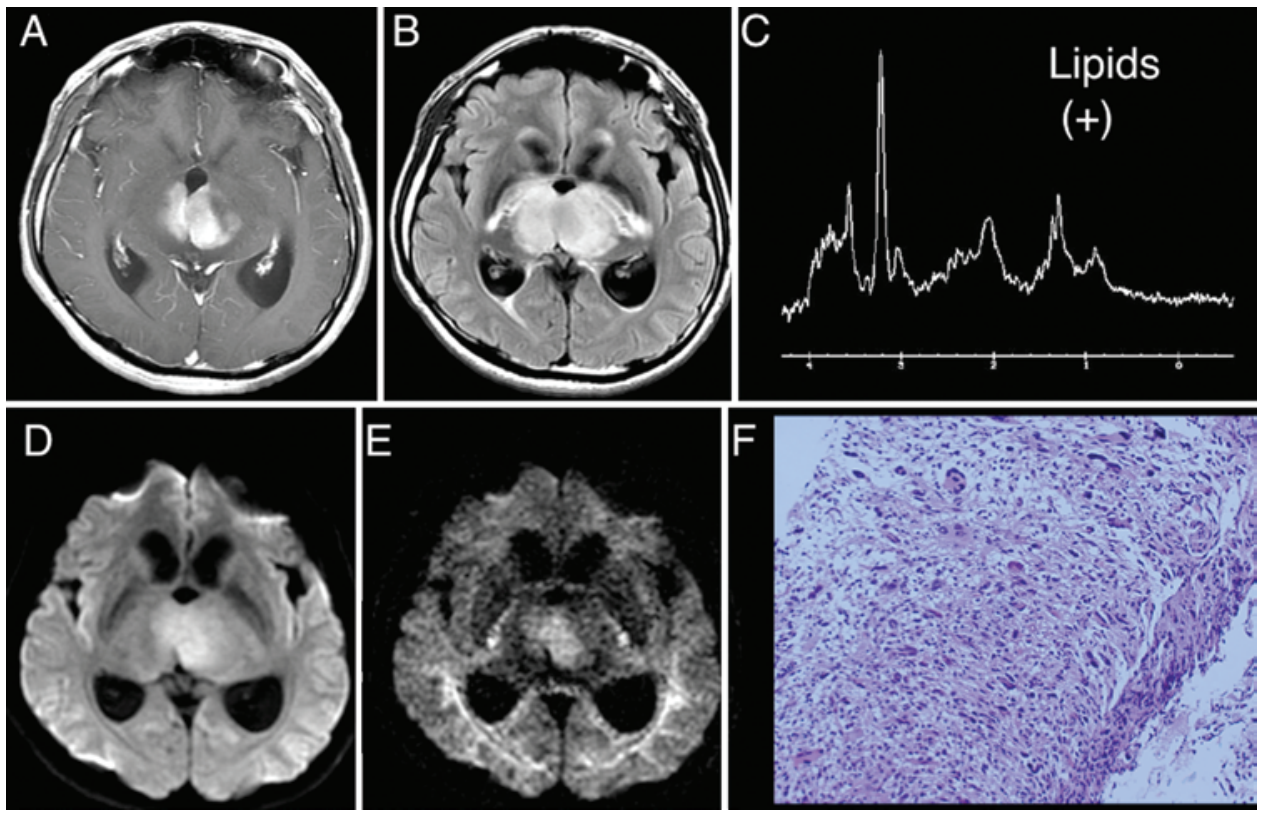

FIG. 3. Glioblastoma in a 31-year-old man. A: Axial contrast-enhanced T1-weighted image showing diffuse tumor enhancement in the thalamus bilaterally. B: Axial FLAIR image showing tumor isointensity to high intensity and hyperintense peritumoral edema. C: Single-voxel ${ }^{1} \mathrm{H}-\mathrm{MRS}$ image (TE $35 \mathrm{msec}$ ) showing a tumor with a positive lipid peak (+1). D and E: Axial diffusionweighted images at b-1000 and b-4000, respectively, showing tumor hyperintensity. F: Photomicrograph of $\mathrm{H} \& \mathrm{E}$-stained tumor tissue. Original magnification $\times 400$. Figure is available in color online only.

also been attributed to in vivo apoptosis or programmed cell death. ${ }^{30}$ Fluorescence microscopy and flow-cytometry measurements have shown that an increase in ${ }^{1} \mathrm{H}-\mathrm{MRS}$ detectable lipids was correlated with an accumulation of cytoplasmic lipid droplets, the so-called lipid bodies.,11

Lipid signals in most brain tumors can be observed when the spectra are acquired at a TE of $<50 \mathrm{msec}$. Mobile lipid resonances are generally observed in contrast-enhancing and necrotic areas of the tumor. Brain tumors tend to be highly heterogeneous and include areas of viable tumor, necrosis, and hemorrhage. Elevated lipid peaks are a characteristic of solid and cystic high-grade gliomas but not of
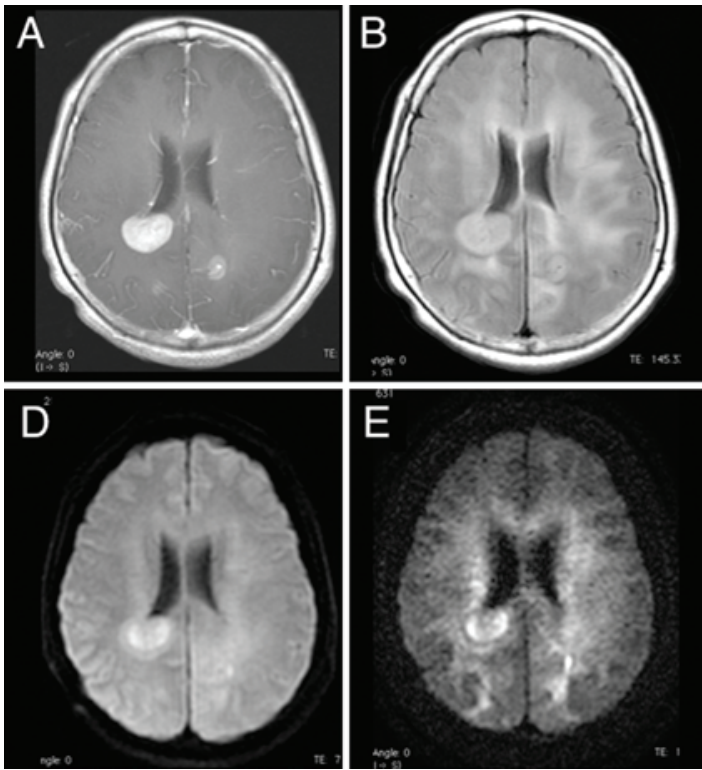
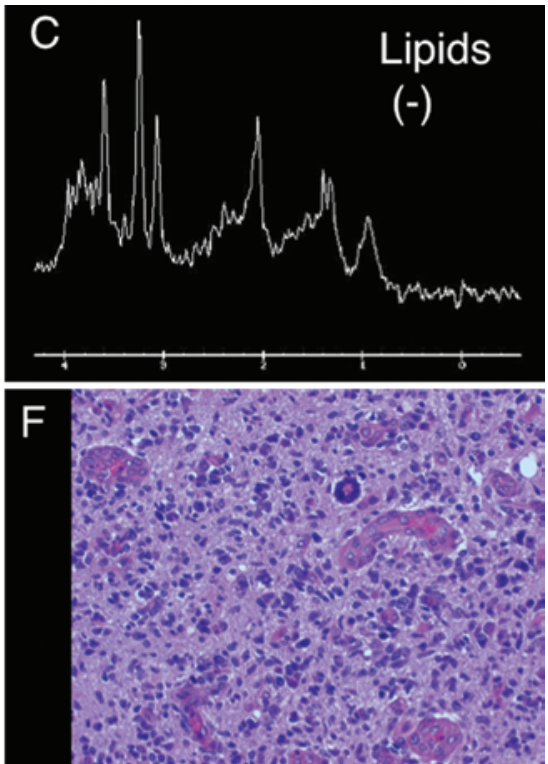

FIG. 4. Glioblastoma in a 66-year-old woman. A: Axial contrast-enhanced T1-weighted image showing diffuse tumor enhancement in the right parietal white matter and a small enhanced lesion in the bilateral parietal lobe. B: Axial FLAIR image showing tumor high intensity and hyperintense deep white matter. C: Single-voxel ${ }^{1} \mathrm{H}-M R S$ image (TE $35 \mathrm{msec}$ ) showing a tumor negative for lipid peaks. D and E: Axial diffusion-weighted images at b-1000 and b-4000, respectively, showing tumor hyperintensity. F: Photomicrograph of $\mathrm{H} \& \mathrm{E}$-stained tumor tissue (magnification $\times 400$ ). Figure is available in color online only. 

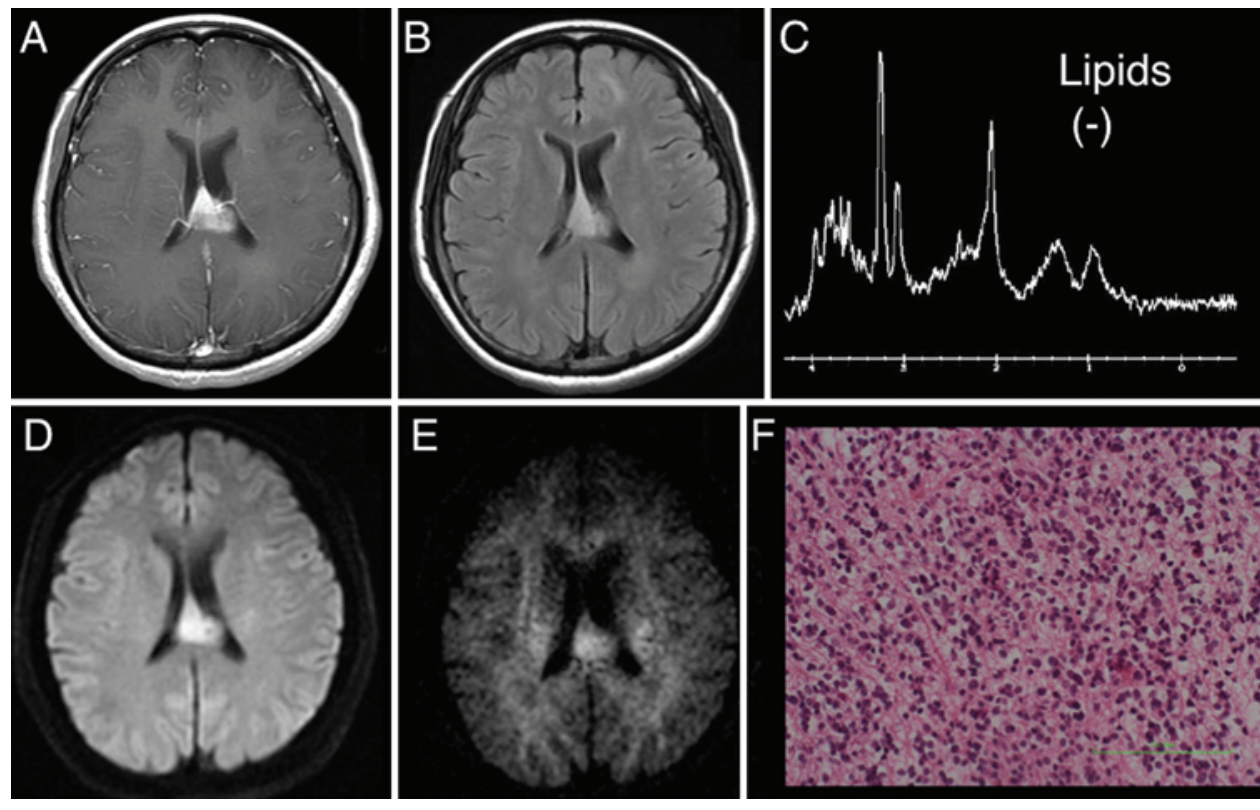

FIG. 5. Anaplastic oligodendroglioma in a 48-year-old woman. A: Axial contrast-enhanced T1-weighted image showing diffuse tumor enhancement in the corpus callosum and left fornix. B: Axial FLAIR image showing tumor high intensity and hyperintense deep white matter. C: Single-voxel ${ }^{1} \mathrm{H}-\mathrm{MRS}$ (TE $35 \mathrm{msec}$ ) image showing a tumor negative for lipid peaks. D and E: Axial diffusion-weighted images at b-1000 and b-4000, respectively, showing tumor hyperintensity. F: Photomicrograph of $\mathrm{H} \& \mathrm{E}-$ stained tumor tissue. Original magnification $\times 400$. Bar $=100 \mu \mathrm{m}$. Figure is available in color online only.

low-grade gliomas. ${ }^{2,22,26,28,29,33}$ Among our homogeneously enhanced gliomas, low- and high-grade tumors did not differ with respect to lipid peaks, which suggests that the higher lipid peaks in high-grade gliomas may be attributable to their cystic or necrotic components. Future studies are necessary to assess the relationship between the size of lipid peaks and glioma grade.

The minimum or mean ADCs of malignant lymphomas are statistically lower than those of gliomas. ${ }^{6,10,15,20,32,35,37}$ The sensitivity and specificity of the ADC for discriminating between malignant lymphomas and gliomas are approximately $80 \%-90 \%$. However, some studies reported no statistically significant difference in the ADCs of glioblastomas and malignant lymphomas, although the ADCs of malignant lymphomas were lower than those of high- grade gliomas. ${ }^{24,31}$ In fact, the overlap in ADC values rendered the differentiation between malignant lymphomas and gliomas on the basis of the ADC difficult. ${ }^{20,31,35}$ For better and more accurate differentiation, other methods (e.g., fractional anisotropy, ${ }^{32}$ perfusion-weighted imaging, ${ }^{37}$ MRS, and PET imaging ${ }^{24,37}$ ) were added to the ADC parameters. Although they were useful, some overlapping between the malignant lymphomas and gliomas persisted. A differential diagnostic advantage of higher b-valuebased DWI in many CNS diseases, including malignant lymphomas, has been reported. ${ }^{6}$ Although we found that b-4000-based DWI was superior to b-1000-based DWI, it was not possible to differentiate all malignant lymphomas from gliomas even with the higher $b$ value.

Our study has some limitations. We focused strictly

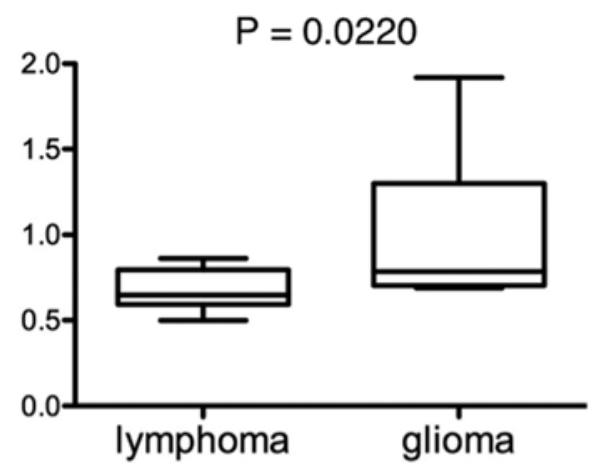

ADC b-1000

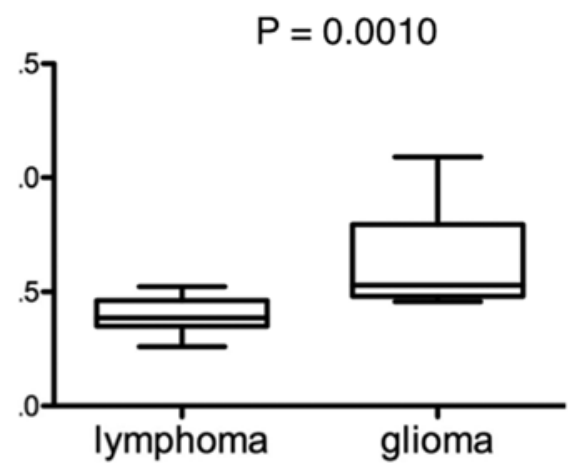

ADC b-4000

FIG. 6. Box plots of $A D C_{\text {MIN }}$ values at $b-1000$ (left) and b-4000 (right). The $A D C_{\text {MIN }}$ values for malignant lymphomas were statistically lower than those for gliomas $(p=0.0220[b-1000]$ and $0.0010[b-4000])$. 
on the differentiation between malignant lymphomas and gliomas. We did not include tumefactive demyelinating lesions or metastatic tumors in our analysis because, at our institution, all metastatic tumors larger than $2 \mathrm{~cm}$ contained some cystic formations or central necrosis. We could not apply our single-voxel ${ }^{1} \mathrm{H}-\mathrm{MRS}$ method to study small tumors. Future studies are necessary to confirm the lipid expression of homogeneously enhanced metastases. Although here we used qualitative rather than quantitative methods to evaluate lipid signals, quantitative studies using LCModel software are in progress in our laboratory.

\section{Conclusions}

${ }^{1} \mathrm{H}-\mathrm{MRS}$ is useful for differentiating between gliomas and malignant lymphomas. The ${ }^{1} \mathrm{H}$-MRS detection of large lipid peaks in tumors without central necrosis is a characteristic of malignant lymphomas. The detection of no or small lipid peaks in an intraaxial tumor without central necrosis is strongly suggestive of glioma.

\section{Acknowledgment}

We thank Ursula Petralia for editorial review.

\section{References}

1. Callot V, Galanaud D, Le Fur Y, Confort-Gouny S, Ranjeva JP, Cozzone PJ: ${ }^{1} \mathrm{H}$ MR spectroscopy of human brain tumours: a practical approach. Eur J Radiol 67:268-274, 2008

2. Calvar JA, Meli FJ, Romero C, Calcagno ML, Yánez P, Martinez AR, et al: Characterization of brain tumors by MRS, DWI and Ki-67 labeling index. J Neurooncol 72:273280, 2005

3. Chawla S, Zhang Y, Wang S, Chaudhary S, Chou C, O'Rourke DM, et al: Proton magnetic resonance spectroscopy in differentiating glioblastomas from primary cerebral lymphomas and brain metastases. J Comput Assist Tomogr 34:836-841, 2010

4. DeAngelis LM: Brain tumors. N Engl J Med 344:114-123, 2001

5. Delikatny EJ, Chawla S, Leung DJ, Poptani H: MR-visible lipids and the tumor microenvironment. NMR Biomed 24:592-611, 2011

6. Doskaliyev A, Yamasaki F, Ohtaki M, Kajiwara Y, Takeshima Y, Watanabe Y, et al: Lymphomas and glioblastomas: differences in the apparent diffusion coefficient evaluated with high $b$-value diffusion-weighted magnetic resonance imaging at 3T. Eur J Radiol 81:339-344, 2012

7. Ducreux D, Wu RH, Mikulis DJ, terBrugge K: Diffusionweighted imaging and single-voxel MR spectroscopy in a case of malignant cerebral lymphoma. Neuroradiology 45:865-868, 2003

8. Fan G: Comments and controversies: magnetic resonance spectroscopy and gliomas. Cancer Imaging 6:113-115, 2006

9. Graham GD, Hwang JH, Rothman DL, Prichard JW: Spectroscopic assessment of alterations in macromolecule and small-molecule metabolites in human brain after stroke. Stroke 32:2797-2802, 2001

10. Guo AC, Cummings TJ, Dash RC, Provenzale JM: Lymphomas and high-grade astrocytomas: comparison of water diffusibility and histologic characteristics. Radiology 224:177-183, 2002

11. Hakumäki JM, Brindle KM: Techniques: Visualizing apoptosis using nuclear magnetic resonance. Trends Pharmacol Sci 24:146-149, 2003

12. Harting I, Hartmann M, Jost G, Sommer C, Ahmadi R,
Heiland S, et al: Differentiating primary central nervous system lymphoma from glioma in humans using localised proton magnetic resonance spectroscopy. Neurosci Lett 342:163-166, 2003

13. Hermann M, Niemitz C, Marafioti T, Schriever F: Reduced phagocytosis of apoptotic cells in malignant lymphoma. Int J Cancer 75:675-679, 1998

14. Hollingworth W, Medina LS, Lenkinski RE, Shibata DK, Bernal B, Zurakowski D, et al: A systematic literature review of magnetic resonance spectroscopy for the characterization of brain tumors. AJNR Am J Neuroradiol 27:1404-1411, 2006

15. Horger M, Fenchel M, Nägele T, Moehle R, Claussen CD, Beschorner R, et al: Water diffusivity: comparison of primary CNS lymphoma and astrocytic tumor infiltrating the corpus callosum. AJR Am J Roentgenol 193:1384-1387, 2009

16. Jayasundar R, Raghunathan P, Banerji AK: Proton MRS similarity between central nervous system non-Hodgkin lymphoma and intracranial tuberculoma. Magn Reson Imaging 13:489-493, 1995

17. Kaminogo M, Ishimaru $\mathrm{H}$, Morikawa $\mathrm{M}$, Ochi $\mathrm{M}$, Ushijima $\mathrm{R}$, Tani M, et al: Diagnostic potential of short echo time MR spectroscopy of gliomas with single-voxel and pointresolved spatially localised proton spectroscopy of brain. Neuroradiology 43:353-363, 2001

18. King NJ, Delikatny EJ, Holmes KT: $1 \mathrm{H}$ magnetic resonance spectroscopy of primary human and murine cells of the myeloid lineage. Immunomethods 4:188-198, 1994

19. King NJ, Ward MH, Holmes KT: Magnetic resonance studies of murine macrophages. Proliferation is not a prerequisite for acquisition of an 'activated' high resolution spectrum. FEBS Lett 287:97-101, 1991

20. Kitis O, Altay H, Calli C, Yunten N, Akalin T, Yurtseven T: Minimum apparent diffusion coefficients in the evaluation of brain tumors. Eur J Radiol 55:393-400, 2005

21. Koeller KK, Smirniotopoulos JG, Jones RV: Primary central nervous system lymphoma: radiologic-pathologic correlation. Radiographics 17:1497-1526, 1997

22. Majós C, Alonso J, Aguilera C, Serrallonga M, Pérez-Martín $\mathrm{J}$, Acebes JJ, et al: Proton magnetic resonance spectroscopy $\left({ }^{1} \mathrm{H}\right.$ MRS $)$ of human brain tumours: assessment of differences between tumour types and its applicability in brain tumour categorization. Eur Radiol 13:582-591, 2003

23. Martínez-Bisbal MC, Celda B: Proton magnetic resonance spectroscopy imaging in the study of human brain cancer. $\mathbf{Q}$ J Nucl Med Mol Imaging 53:618-630, 2009

24. Matsushima N, Maeda M, Umino M, Suzawa N, Yamada T, Takeda K: Relation between FDG uptake and apparent diffusion coefficients in glioma and malignant lymphoma. Ann Nucl Med 26:262-271, 2012

25. Mohan S, Verma A, Lim CC, Hui F, Kumar S: Lipid resonance on in vivo proton MR spectroscopy: value of other metabolites in differential diagnosis. Neuroradiol J 23:269278,2010

26. Opstad KS, Ladroue C, Bell BA, Griffiths JR, Howe FA: Linear discriminant analysis of brain tumour ${ }^{1} \mathrm{H}$ MR spectra: a comparison of classification using whole spectra versus metabolite quantification. NMR Biomed 20:763-770, 2007

27. Panigrahy A, Krieger MD, Gonzalez-Gomez I, Liu X, McComb JG, Finlay JL, et al: Quantitative short echo time 1H-MR spectroscopy of untreated pediatric brain tumors: preoperative diagnosis and characterization. AJNR Am J Neuroradiol 27:560-572, 2006

28. Poptani H, Gupta RK, Jain VK, Roy R, Pandey R: Cystic intracranial mass lesions: possible role of in vivo MR spectroscopy in its differential diagnosis. Magn Reson Imaging 13:1019-1029, 1995

29. Poptani H, Gupta RK, Roy R, Pandey R, Jain VK, Chhabra 
DK: Characterization of intracranial mass lesions with in vivo proton MR spectroscopy. AJNR Am J Neuroradiol 16:1593-1603, 1995

30. Schmitz JE, Kettunen MI, Hu DE, Brindle KM: 1H MRSvisible lipids accumulate during apoptosis of lymphoma cells in vitro and in vivo. Magn Reson Med 54:43-50, 2005

31. Server A, Kulle B, Maehlen J, Josefsen R, Schellhorn T, Kumar T, et al: Quantitative apparent diffusion coefficients in the characterization of brain tumors and associated peritumoral edema. Acta Radiol 50:682-689, 2009

32. Toh CH, Castillo M, Wong AM, Wei KC, Wong HF, Ng SH, et al: Primary cerebral lymphoma and glioblastoma multiforme: differences in diffusion characteristics evaluated with diffusion tensor imaging. AJNR Am J Neuroradiol 29:471-475, 2008

33. Wright AJ, Fellows G, Byrnes TJ, Opstad KS, McIntyre DJ, Griffiths JR, et al: Pattern recognition of MRSI data shows regions of glioma growth that agree with DTI markers of brain tumor infiltration. Magn Reson Med 62:1646-1651, 2009

34. Yamasaki F, Kurisu K, Kajiwara Y, Watanabe Y, Takayasu T, Akiyama Y, et al: Magnetic resonance spectroscopic detection of lactate is predictive of a poor prognosis in patients with diffuse intrinsic pontine glioma. Neuro Oncol 13:791801, 2011

35. Yamasaki F, Kurisu K, Satoh K, Arita K, Sugiyama K, Ohtaki M, et al: Apparent diffusion coefficient of human brain tumors at MR imaging. Radiology 235:985-991, 2005

36. Yamasaki F, Takaba J, Ohtaki M, Abe N, Kajiwara Y, Saito
T, et al: Detection and differentiation of lactate and lipids by single-voxel proton MR spectroscopy. Neurosurg Rev 28:267-277, 2005

37. Yamashita K, Yoshiura T, Hiwatashi A, Togao O, Yoshimoto $\mathrm{K}$, Suzuki SO, et al: Differentiating primary CNS lymphoma from glioblastoma multiforme: assessment using arterial spin labeling, diffusion-weighted imaging, and ${ }^{18} \mathrm{~F}$-fluorodeoxyglucose positron emission tomography. Neuroradiology 55:135-143, 2013

\section{Author Contributions}

Conception and design: Yamasaki. Acquisition of data: Yamasaki, Takayasu, Nosaka, Amatya, Doskaliyev, Akiyama, Takeshima. Analysis and interpretation of data: Yamasaki, Takayasu, Nosaka, Doskaliyev. Drafting the article: Yamasaki. Critically revising the article: Yamasaki. Reviewed submitted version of manuscript: Yamasaki. Approved the final version of the manuscript on behalf of all authors: Yamasaki. Statistical analysis: Yamasaki. Administrative/technical/material support: Yamasaki, Tominaga, Kurisu. Study supervision: Yamasaki, Sugiyama, Kurisu.

\section{Correspondence}

Kaoru Kurisu, Department of Neurosurgery, Graduate School of Biomedical and Health Sciences, Hiroshima University, 1-2-3 Kasumi, Minami-ku, Hiroshima 734-8551, Japan. email: kuka422@hiroshima-u.ac.jp. 